\title{
CEsifo WORKING

\section{Tax Housing or Land? Distributional Effects of Property Taxation in Germany}

Rafael Barbosa, Simon Skipka 


\section{Impressum:}

CESifo Working Papers

ISSN 2364-1428 (electronic version)

Publisher and distributor: Munich Society for the Promotion of Economic Research - CESifo

$\mathrm{GmbH}$

The international platform of Ludwigs-Maximilians University's Center for Economic Studies and the ifo Institute

Poschingerstr. 5, 81679 Munich, Germany

Telephone +49 (0)89 2180-2740, Telefax +49 (0)89 2180-17845, email office@cesifo.de

Editor: Clemens Fuest

www.cesifo-group.org/wp

An electronic version of the paper may be downloaded

- from the SSRN website: www.SSRN.com

- from the RePEc website: www.RePEc.org

- from the CESifo website: www.CESifo-group.org/wp 


\title{
Tax Housing or Land? Distributional Effects of Property Taxation in Germany
}

\begin{abstract}
Despite its theoretical merits, Land Value Taxation (LVT) is not a common policy instrument in most countries. One of the main reasons is uncertainty regarding its distributional impacts. This uncertainty has not been settled by the literature, due to a lack of appropriate data at the household level. We overcome this obstacle by the construction of a unique household level dataset for a sample of German homeowners in 2017. The data collected allows us to study the differences in distributions of land and property values and the resulting distributional effects of implementing a LVT compared to a standard property tax. Our results are as follows. First, we find revenue neutral LVT rates to be around $0.6 \%$ in our sample. Second, we find the share of land value in property value on average to be $33 \%$ with considerable household heterogeneity, both within and between regions. Third, we find a LVT to be equally progressive if implemented at the federal level, but less progressive if implemented at the regional level, since, although land values are more concentrated than property values, they are not as strongly correlated with income. Quantitatively a revenue-neutral reform from a standard property tax to a LVT at the regional level would increase the average tax burden of the lowest income quintile of homeowners by $25 \%$.
\end{abstract}

JEL-Codes: H200, H710, R200.

Keywords: land, housing, land value taxation, property taxation, distributional assessment.

Rafael Barbosa

Department of Economics

European University Institute

Florence / Italy

rafael.barbosa@eui.eu

\author{
Simon Skipka \\ Department of Economics \\ European University Institute \\ Florence / Italy \\ simon.skipka@eui.eu
}

September, 2019

We thank Denis Gorea, Ramon Marimon and Dominik Sachs as well as seminar participants at the EUI for helpful comments and discussions. Further, we thank everybody at the SOEP for their kindness and support during the research visit in Berlin. Finally, we thank Andrea Galeotti for his financial support. 


\section{Introduction}

Land value taxation is a type of property taxation which falls solely on the unimproved value of land, as opposed to standard property tax regimes which take the total value of property (unimproved land plus structures built upon it) as tax base. Since Adam Smith, numerous economists have pointed to the benefits of land value taxation (LVT) over standard property taxation. Most importantly, land, being physically more inelastic than housing, provides a far less distortionary source of revenue for governments.

Despite its theoretical merits, LVT is not widely used. In 2019, from the 36 OECD countries only Denmark, Estonia and Lithuania levy a nationwide LVT. One reason for the small number of LVT regimes is that, historically, a standard property tax has been perceived as more progressive. The idea behind it is that standard property taxation includes an additional part of a household's wealth in the tax base, in the form of structures. Due to this additional component, property values are commonly perceived as a better tag for prosperity than land values. However, in the last years this view has been under scrutiny in academia.

In particular, the issue of land value appreciation has been identified as one of the main drivers of increasing inequality. Rognlie (2015) demonstrates that Piketty's increasing share of capital income is, for the most part, a consequence of increasing value of housing. Furthermore, as pointed out by Stiglitz (2015), this trend in housing wealth is driven primarily by the location premium, rather than by increases in construction costs, meaning land value accounts for an increasing share of total housing value and that its distribution is becoming increasingly more unequal. These findings suggest taxing land values could, in general, be an effective way to redistribute from the top of the wealth distribution to the rest.

Empirical evidence on this matter is scarce and inconclusive. Some attempts have been made to evaluate the distributional impact of a LVT in different US metropolitan areas. The studies find conflicting evidence and suffer under data limitation problems. In this regard, the empirical literature on the distributional impact of a LVT is not yet settled. Our project contributes to this literature, offering fresh evidence from a unique data set for one of the bigger OECD countries, Germany.

Our newly collected data set is superior to previous sources on two dimensions. First, the literature has so far relied on own estimation techniques to determine land values. However, this estimation is ambiguous, especially if the market for unimproved lots is thin. Thus, if a researcher's estimation procedure structurally differs from the official procedure, a distributional assessment will naturally be biased. We overcome this problem by using official land value estimates directly. Whatever estimation procedure is underlying our land values, it will have a direct distributional impact. Second, so far there exists no data set linking households' land values to other characteristics like income. We overcome this problem by using a geo-match approach to add data on land values to a high quality household survey containing a representative sample of German households.

Based on our data set, we provide (new) answers to the following research questions: How do holdings of land and property values differ across the population? How do the differences relate to income? How do the differences vary across and within regions? What is the quantitative impact of these differences when comparing a standard property tax regime to one based on land values?

To address our first research question, we analyze the distribution of land and property value independently. The differences between both distributions are significant. In particular, land values are much more concentrated 
than property values. While for property values the Gini-coefficient is 0.35 , for land values we find the coefficient to be 0.48 . These results suggest the distribution of tax burdens would be much less even under a LVT.

In a next step, we compute the land to property value ratio for each household in our sample. We demonstrate that a household's Land Value Share, in relation to the average Land Value Share, is a sufficient statistic to determine winners and losers from a revenue-neutral switch to a LVT. A household with a Land Value Share lower than the average wins under a LVT regime and vice versa. Accordingly, if the Land Value Share was the same across households, a switch in tax regimes would not trigger any change in tax burden. We find the distribution of the Land Value Share exhibits a sizable variance around the sample mean of 0.33 , showing a switch in the tax regime triggers significant changes in burden for a large part of the population. In numbers, tax burden differs by at least $22 \%$ for half of the population.

Relating those differences in tax burden to household income constitutes the distributional assessment of a LVT, the main objective of this paper. Initially, it is important to state that our data clearly shows both LVT and property taxation to be progressive in nature. So, the distributional analysis is designed to determine which of the two is more progressive.

In this analysis, we initially establish a relation between income and the Land Value Share. Income has an effect on the share through its impact on land and structure value. In fact, it can be shown that, if the income elasticity of structure value exceeds the income elasticity of land value, the income elasticity of the Land Value Share is negative. In such cases, qualitatively, a switch to LVT would be regressive.

A prevalent characteristic of property taxation is its regional scope. In most countries property taxes are levied on a sub-federal level, in Germany it is one of the most important municipal taxes. For this reason, our main analysis works under the assumption of regional revenue-neutrality. Imposing that restriction we estimate an income elasticity of land value of 0.2 and an income elasticity of structure value of 0.35 . Accordingly, the income elasticity of the share is -0.15 , indicating a regressive impact of a LVT, compared to a property tax.

An intuition behind this result is that structure value is easier to adjust than land value. Changing the land value by altering the plot size is oftentimes not feasible due to physical constraints, changing the land value by moving to a different neighborhood triggers moving costs. In general, the argument applies independent of the direction of adjustment. However, in particular for the moving we find an accentuated downward rigidity. This means although it is difficult to find high income households in low land value neighbourhoods, it is not uncommon to find low income households in high land value neighbourhoods, living in houses with low structure value.

Quantitatively, our results show that, on average, implementing a LVT rather than a property tax reduces the difference in yearly tax burden between the first and fifth income quintile by $90 €$. This number must be seen through the lenses of traditionally low property tax rates in Germany. We find revenue neutral land value tax rates in our data to be $0.6 \%$ on average, translating into an average annual tax burden of $800 €$. Setting the change in relation to the property tax burden, we find households in the first income quintile experience, on average, a tax burden increase of around $25 \%$. So, in the current context of rising property tax rates, our results have a relevant quantitative impact for future policy debates.

Finally, beyond the average, we find a significant dispersion in tax burdens within each income quintile. For 
example in the lowest income quintile, despite an average increase of tax burden by $25 \%$, the tax burden under a LVT is smaller for $45 \%$ of the households. This heterogeneity shows that income by itself should not be taken as a reliable predictor of the difference in tax burden.

After having laid out our results, we would like to point out that our project arrives at a time in which LVT has become a hot topic in the policy debate.

First, over the last decades several OECD countries, including Germany, have been facing a housing crisis with rents and house prices in major cities soaring. Several reports, such as Mirrlees et al. (2011) and the OECD Fiscal Federalism report of 2016 point to LVT as a promising tool to curb rent hikes by promoting housing construction while also efficiently raising revenue for the government.

Second, the use of German data for this project is well timed as property taxation in Germany is under a process of major reform. In early 2018, the German constitutional court has ruled the property tax must be replaced. Meanwhile, economic research institutes have pointed to a LVT as a possible instrument to supersede it. Additionally, the German government has recently set goals to sharply increase housing supply in the coming years to fight the skyrocketing property prices and rents hurting households in the country. This project can provide a basis to evaluate the suitability of different policy alternatives in achieving these goals. Further, in the latter part of this paper we provide a brief analysis of a LVT's distributional impact when moving away from the current system of property taxation in Germany.

This paper contributes to the literature on several fronts. The main contributions are the empirical identification of the household level distribution of land and property values in a major developed country and the estimation of the distributional impacts of land value taxation and property taxation in relation to their progressivity.

Besides the main contribution, we identify other relevant secondary contributions. First, by building a novel household level dataset with information on property and land holdings. Second, by computing relevant measures of land value at the regional level, enabling the estimation of an taxable land value and revenue neutral land value tax rates in Germany. Finally, through the policy experiments carried out, this project contributes to the ongoing discussion on the reformulation of the property tax system in Germany, by shedding light on the likely winners and losers of different types of property taxation (assuming the current level of revenues is to be maintained).

The rest of the paper is structured as follows. In Section 2 we briefly discuss the literature on distributional aspects of land value taxation. Section 3 explains the construction of the data set used in our analysis. Section 4 presents relevant regional level results. Section 5 contains the distributional assessment at the household level. Section 6 discusses the distributional impact of a LVT moving away from the current property tax regime in Germany. Finally, Section 7 concludes.

\section{Literature Review}

Theoretical literature addressing the efficiency gains of implementing a LVT is relatively abundant. Property taxation contains an implicit tax on capital which hinders the accumulation of housing capital, creating an 
inefficiently low level of housing supply in the economy. In contrast, LVT taxes an asset in (quasi) fixed supply, so that a switch in tax base would remove the physical distortion. Aura and Davidoff (2012) for example, show how optimal property tax rates increase with the share of pure land rents to structures.

Empirically, there have been some attempts to assess the impact on housing supply of switching from a property tax to a LVT. These papers usually rely on using policy changes in specific cities where property taxation follows a two-rate system, taxing land and structures at different rates. Oates and Schwab (1997) focuses on the case of Pittsburgh in the US during the 1980s. Results show strong evidence that switching towards more land value taxation increases construction and overall housing supply against a control group of other cities with similar characteristics, corroborating theoretical arguments.

Few attempts have been made to quantify the distributional aspects of taxing land values instead of property values. England and Zhao (2005) and Plummer (2010) study changes in two-rate property tax systems and find conflicting results regarding the progressivity of the measure. The former finds evidence for a regressive tendency in the case of New Hamphshire, and the latter finds moving to a LVT in Texas would be slightly more progressive, while also shifting the tax burden away from single-family properties and unto other property classes. However, these papers rely on regional level data and thus are unable to pick up on cases of low income households in high income regions or vice-versa.

During the discussion about the introduction of a LVT in Germany, several policy reports stressed the importance of distributional consequences and provided intial evidence. A recent example of this kind is Fuest

et al. (2018). The authors discuss distributional consequences between households living in multiple and single family houses, showing a LVT shifts a significant portion of the tax burden to single family house owners. Their study assumes representative type of houses, so that they cannot discuss the idiosyncratic differences in quality and size. Further, the authors are not able to quantitatively link the propensity of living in a certain type of house to a household's income.

\section{Data}

This paper aims first to fill a gap in the literature by using German data to tease out the distributions of land and property values at a household level for a sample of homeowner households which is broadly representative of the German population. Furthermore, we analyze how the holdings of these assets correlate with income to assess progressivity. Such a breakdown of total housing wealth in land and structures has not been attempted at a national scale. This section lays out in detail the construction of our unique data set, which allows us to perform the distributional analysis in the paper.

\subsection{Household Survey}

The socioeconomic panel (SOEP) is a German household survey conducted by Deutsches Institut für Wirtschaftsforschung (DIW). The SOEP provides the basic information on households in our project. We use SOEP data from 2017 (wave 34). For our analysis, the most important variables in the SOEP are those related to income and real estate property. Monthly income is a standard variable in the SOEP included every year. Information 
about property is less frequent as it is part of a specific wealth module which is only carried out every five years, at last in 2017. In this module, households provide information regarding their wealth holdings, including the value of their primary residence. The information is only provided by owner-occupiers. As primary residence value is a necessary information for the later analysis, we are forced to restrict the sample to owner-occupiers.

The SOEP does not include a decomposition of property value in land and structures value. We use other sources of data to estimate the land component of the property value. In this decomposition, we employ other information from the SOEP, like the number of dwellings within the household's housing structure.

\subsection{VALKIS + M}

This section introduces the dataset we need to derive the land component of a household's property value, VALKIS + M. It combines information from three different data sources: the German land registry (Amtliches Liegenschaftskataster), the official dataset on land values (Bodenrichtwerte), the German statistical offices' regional data base (Regionaldatenbank des Statistischen Bundesamtes). We introduce the individual parts in isolation and describe, how they are brought together in order to generate VALKIS + M.

\subsubsection{ALKIS}

ALKIS is the digitized version of the official German land registry. The smallest geographical unit entered in ALKIS is a lot. Our analysis proceeds by using the lot as the unit of observation. For each lot, ALKIS contains information on the type of usage as well as the addresses attributed to the lot. The usages range from residential, industrial and commercial land to forests, rivers and streets. An address is attached to a lot for every independent unit of housing that requires postal correspondence. Historically, a lot describes an economic or contextual unit: a river, a street, a piece of residential land owned by an individual. However, over time, this correspondence has been diluted, so that currently ALKIS contains lots with multiple usages, e.g. lots with farmland and residential land, as well as lots with multiple addresses. In order to later account for those incongruities, we keep the information on the number of addresses and the type of usages for all lots. Finally, ALKIS does not contain information on the size or characteristics of any potential structures on the lot.

In sum, we use ALKIS to generate a dataset with lots as the unit of observation. For each lot, we have precise information on the usage as well as the number of addresses. The geographic extent of our dataset spans the whole surface of five German states: Berlin, Hamburg, Niedersachsen, Nordrhein-Westfalen, Thüringen. Data on the remaining states was not available due to data privacy The states under consideration have a joint population of about 35 million. The sample of states is representative, consisting of metropolitan as well as rural areas and states from former eastern and western Germany.

\subsubsection{Official Land Value Data}

Bodenrichtwerte are the results of annual assessments conducted by regional councils of real estate experts (Gutachteraussschüsse für Immobilienwerte). They are used as measure of land value throughout our project.

\footnotetext{
${ }^{1}$ Each state has specific policies regarding the availability of this data.
} 
In Germany, these land values are used frequently by banks to determine the value of a collateral or in insolvency proceedings to assess the wealth of a defaulting debtor. In the context of the current policy debate on the property tax reform in Germany, Bodenrichtwerte are designated to be used as a main source of information to assess a household's future tax burden. The derivation of the land values is twofold.

First, the regional councils define land value zones as narrow geographical areas for which the land value does not significantly differ within. The split is based on the experience of the council as well as historic and current information on sales prices of property and land. The area of land value zones depends on the heterogeneity of the neighborhood under consideration, however, it rarely spans an area of more than one square kilometer. Second, the regional councils determine the land values per land value zone. Land values are stated separately for agricultural, commercial and residential land 2 The zone-specific land values are derived from the collection of land and property sales inside a land value zone within the last years. The preferred source of information is the price of unimproved lots. If not available, land values are derived from the price of improved lots, using hedonic price regressions, or the price of unimproved lots in different land value zones with similar characteristics. Figure 1 shows a map of land values in the municipality of Düsseldorf, where one can see the geographical precision of the land value districts.

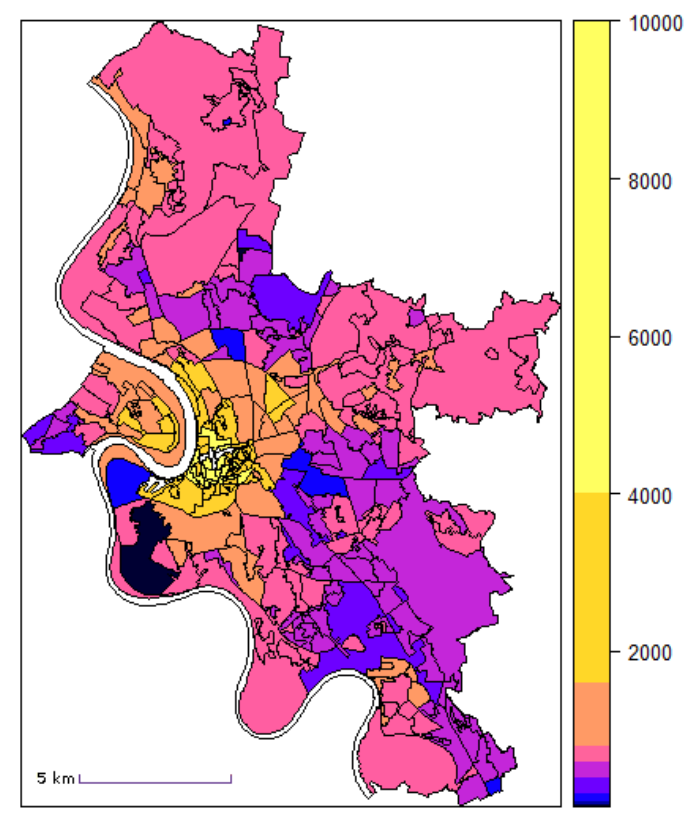

Figure 1: Residential land values in Düsseldorf

Regions in white are non-residential. Values are in Euros per square meter.

In sum, we use the official land value statistics to generate a data set with land value zones as unit of observation. Each land value zone is defined so that land values within a zone do not significantly differ. Further, the data set contains information on different kind of land values within a zone: agricultural, commercial and residential land value.

\footnotetext{
${ }^{2}$ In certain cases, the land values even differ for residential land used for the construction of single or multiple family houses.
} 


\subsubsection{VALKIS}

VALKIS is the result of a spatial joint of ALKIS and the official land value data. The unit of observation is the lot. In particular, we take each lot from ALKIS and find the corresponding land value zone in the official land value data ${ }^{3}$. Conditional on the lot's actual usages, captured in ALKIS, we attach the relevant zonal land values to the lot, agricultural, commercial or residential. In sum, VALKIS is a geo-referenced data set with the lot as the unit of observation, the information per lot is: the actual usages, the number of addresses, the land value per $m^{2}$ for every type of lot usage.

\subsection{4 $+\mathrm{M}$}

$+\mathrm{M}$ summarizes information on the regional level, the unit of observation is the municipality. The data is collected from different sources and reflects the living conditions in a municipality in terms of amenities, prices and taxes.

A municipality's degree of urbanization is proxied by population density, a municipality's recent trend in attractiveness, by population growth between 2012-2017. Data on both is gathered from the German statistical offices' regional database. In order to get information on the price level, especially with regard to land prices, we determine the average land value within a municipality. For that, we take the average of a municipality's zonal land values, weighed by the share of residential land contained in a zonf 4 At last, we determine the revenue neutral land value tax rates. Any form of property taxation has traditionally been a municipal tax in Germany and will certainly remain so after the coming reform. Thus, the land value tax rates have to be chosen to guarantee revenue neutrality on the level of the municipality. If we denote by $\tau_{i}$ the revenue neutral tax rate in municipality $i$, it is defined by $\tau_{i} \times L V_{i}=T R_{i}$, where $T R_{i}$ represents the current tax revenues and $L V_{i}$ the aggregate land value of municipality $i$. Rearranging, the revenue neutral tax rate is given by $\tau_{i}=\frac{T R_{i}}{L V_{i}}$. We can derive the denominator, using the information stored in VALKIS. Regarding the numerator, we once again gather information from the regional database.

Finally, we spatially join VALKIS and + M. The final output is the geo-referenced data set VALKIS + M with the lot as the unit of observation, the information per lot is: the actual usages, the number of addresses, the land value per $\mathrm{m}^{2}$ for every type of lot usage, Population Density, Population Growth, Average Land Value, Revenue-neutral land value tax rate.

\subsection{SOEP 2.0}

SOEP 2.0 is the product of a spatial join of SOEP and VALKIS+M, using the SOEPgeo dimension. This unique feature of the SOEP allows us to access the geo-coordinate of each household in the survey. The access is tightly regulated and must be carried out in the DIW facilities in Berlin. We use SOEPgeo to identify the lot in which a household lives and append the respective lot data from VALKIS $+\mathrm{M}$ to the original household

\footnotetext{
${ }^{3}$ The correspondence is given by the spatial reference of both data sets and executed using standard spatial techniques of the statistical software program R.

${ }^{4}$ For later sensitivity analysis we generate a second measure of average land value, using the weighed zonal land values within $20 \mathrm{~km}$ distance of each lot.
} 
survey data.

In addition to combining the information, we create additional variables which require the use of data from both of the sources. A crucial variable is the residential size per household. To construct the variable, we take the full lot residential size and divide it by the number of addresses in that lot, from the ALKIS. We further divide by the number of households in each address, which we obtain from the SOEP, to obtain the residential size per household. To exemplify, let's take the total residential size of the lot to be $1000 \mathrm{~m}^{2}$. Then, if, for example, in the ALKIS the lot is associated with two addresses (two independent residential buildings), and if in the SOEP we observe there are four households in the building, we impute the residential size of our particular household in our sample to be $\frac{1.000 \mathrm{~m}^{2}}{2 \times 4}=125 \mathrm{~m}^{2}$.

The computation relies on two assumptions, which should be addressed. First, splitting lot land size by the number of addresses in the lot assumes that, in case of multiple addresses, each address occupies an equal fraction of the lot's size. Second, we assume that for multiple family houses, households share the residential size equally. Although these assumptions will lead to errors in specific cases, both reflect the benchmark in the German housing market and, thus, should not influence overall results. The land value component of a household's property value then derives as the product of residential size and residential land value per $m^{2}$.

In sum, SOEP 2.0 is a data set with the household as the unit of observation. It carries the variables from the SOEP and augments them with a decomposition of property value in land and structure value. Further, for each household it adds regional information on: Average Land Value, Population Density and Growth, revenue neutral land value tax rat 5

\subsubsection{Quality of Matching}

This section discusses the reliability of our geo-match approach in determining a household's land value component. The fact that our final data set was built from several unrelated sources, each with its own shortcomings, and using a self designed geographical matching algorithm, might raise doubts regarding the validity of our SOEP 2.0 data. We try to address such concerns by evaluating if the relation between self reported property values and imputed land values are consistent with each other.

Given that property value is the sum of land and structure value, an increase of one euro in land value, keeping constant the structure value, should imply an increase of one euro in property value. Thus, if our matching is accurate, we should be able to observe this relation in our sample. To test this hypothesis we run a regression of property value (from the SOEP) on the land value we imputed, controlling for structure value. We do not have a variable of structure value in the survey data. If we did, computing the land value component would have been trivial. Instead, we proxy structure value using SOEP variables with information on the quantity and quality of structures: size of the house (in $\mathrm{m}^{2}$ ), and condition of the house (a categorical variable with four levels). We run the following model: $P V_{i}=\beta_{0}+\beta_{1} L V_{i}+\beta_{2}$ size $_{i}+\beta_{3}$ condit $_{i}+\epsilon_{i}$. Results from this regression show a coefficient for $\beta_{1}$ equal to 1.003, not statistically different from one, consistent with our conjecture. This result reassures us regarding the validity of our geo-match approach and the results we will discuss from here onward.

\footnotetext{
${ }^{5}$ Appendix A contains a diagram representing the construction of SOEP 2.0.
} 


\section{Regional Data Analysis}

This section provides a summary of the data collected at a regional level, before proceeding to the household level data.
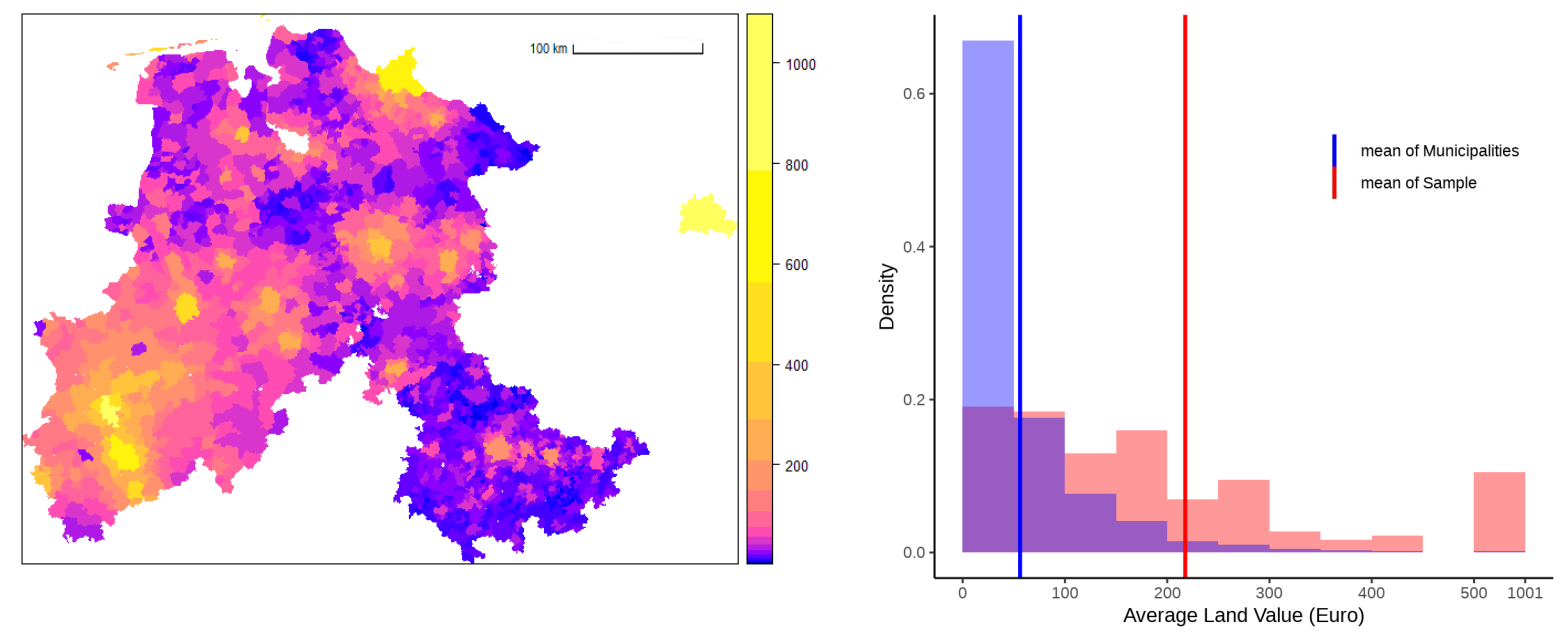

Figure 2: Municipal average land values

The blue (red) distribution in the right panel shows the distribution with municipalities (sample households) as the unit of observation. Values are in Euro per $\mathrm{m}^{2}$.

The map in Figure 2 shows average land value per municipality (Gemeinde) in the five states in our analysis, comprised of a total of 2214 municipalities. It presents a fairly large contiguous region of Germany (apart from Berlin), with different characteristics. The first thing to notice is the heterogeneity in average land values. The lowest municipal average land values in our sample are under $10 €$ per $m^{2}$, while for Berlin (the highest) the average is $1000 €$. Very few municipalities exhibit average land values higher than $200 €$, as can be seen from the blue distribution in the right panel of figure 2 Nevertheless, a substantial number of observations at the household level are from these municipalities, as can be seen from the red distribution in the same panel.

Our regional data allows for the computation of other interesting aggregate statistics. Total land value in the region we are considering is over $1.5 €$ trillion, 1.2 times the region's GDP. The magnitude is in line with recent estimates from the US, e.g. Larson (2015). $90 \%$ of the total land value is non-agricultural, the rest being agricultural. These numbers establish land value as a sizable, mostly untapped tax base.

Having computed total land values in each municipality and collected the respective current property tax revenues, we have computed the necessary land value tax rates which would ensure revenue neutrality. The histograms of these revenue neutral land value tax rates are presented in Figure3 Again, in blue the distribution of municipalities, and in red the distribution of households in our sample. Around $70 \%$ of municipalities would need to set a tax rate between 0.25 and $1 \%$ of land value. The maximum revenue-neutral tax rates we find are around $2 \%$. The household distribution is even more skewed to the left, as a result of more densely populated areas having lower revenue neutral tax rates, on average. 


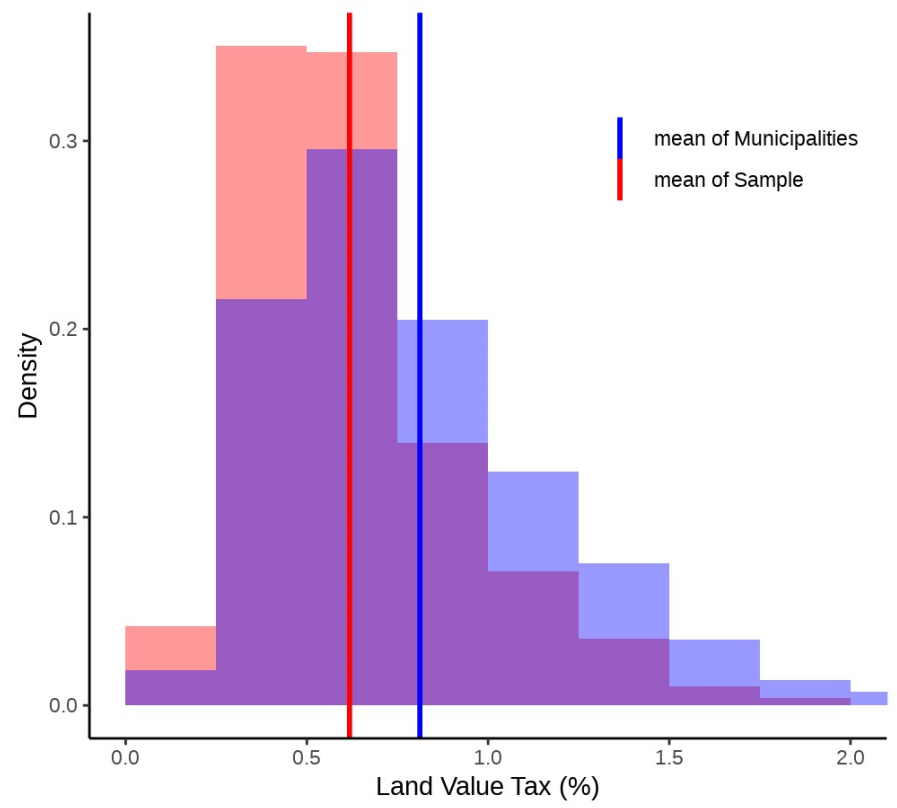

Figure 3: Distribution of revenue neutral land value tax rates

The blue (red) distribution in the right panel shows the distribution with municipalities (sample households) as the unit of observation. The vertical lines represent the mean of each of the distributions.

\section{Analysis of the SOEP 2.0}

This section contains the main analysis of our paper. We start by presenting the distribution of land and property value in the sample and introduce the concept of Land Value Share, which provides a sufficient statistic to qualitatively determine winners and losers from a LVT. We proceed by relating the change in tax burden to income and split up the mechanism in intuitive parts. Finally, the last subsection contains a quantitative assessment of the tax regimes.

\subsection{Distributions of Land and Property Value}

The first question we address is how the distributions of land and property values differ in our sample. Table 1 provides some initial statistics. Mean property value in our sample is $261.000 €$, while mean land value is $86.500 €$. The distribution of land exhibits a higher variance than the distribution of property when controlling for the level of each asset. Standard deviation of property value is $88 \%$ the value of the mean, while for land value this number is $124 \%$. Looking at aggregate statistics for total holdings of property and land value in our sample, we see that aggregate land value is $204 €$ million. This accounts for $33 \%$ of aggregate property value, which stands at over $615 €$ million. The aggregate level of land or property values are important as they represent the size of the tax base of a land value or property tax. 


\begin{tabular}{lccccc}
\hline & Property value $(€)$ & Land value $(€)$ & Land value share & Lot size & House size \\
\hline Mean & 260,793 & 86,495 & 0.33 & 603.41 & 134.14 \\
St. dev & 230,018 & 106,875 & 0.22 & 549.76 & 46.67 \\
Minimum & 4,590 & 980 & 0.01 & 7.56 & 20.00 \\
1st Quartile & 150,000 & 32,640 & 0.17 & 255.00 & 103.00 \\
Median & 220,000 & 58,927 & 0.27 & 500.00 & 126.00 \\
3rd Quartile & 300,000 & 105,300 & 0.44 & 779.00 & 155.00 \\
Maximum & $5,000,000$ & $2,536,800$ & 1.19 & $6,862.00$ & 450.00 \\
Sum & $615,210,820$ & $204,042,818$ & & & \\
\hline
\end{tabular}

Table 1: Housing statistics

The sample consists of homeowners in the DIW-SOEP, being residents of the German states Berlin, Hamburg, Lower

Saxony, Northrhine-Westfalia und Thuringa. The sample size is 2,359. Lot and House size in $m^{2}$

To assess the concentration of these assets in our sample, we computed Gini coefficients. The value for property is 0.35 , while for land it is 0.48 . For reference, the Gini coefficient for income is 0.28 . It seems land is significantly more concentrated than property in our sample, value wise. If one were to assume the distribution of these assets match the distribution of income on a household level (the household with highest income would also own the most valuable property and land, while the poorest the less valuable property and land), then taxing land would naturally be more progressive than taxing property value. However, this conclusion depends crucially on how these distributions relate to each other and how they relate to income. First, we investigate the link between land and property values.

\subsection{Land Value Share}

We define the Land Value Share (LVS) as the ratio of land to property value for a given household. This statistic allows one to have a first idea of the magnitude of potential distributional effects. If the distribution were concentrated at a single point there would be no scope for any household to win or lose from a LVT, comparing to a property tax. Dispersion of this measure signifies the existence of households with low (high) land value and high (low) property value, which would thus benefit from paying taxes on their land (property).

In the third column of Table 1 we see the statistics for the LVS. The mean is 0.33 while the standard deviation of this measure is 0.22 , a considerably high number, indicating our sample has many households with low property value and high land value, and vice-versa. We can see this more clearly in Figure 4 showing the distribution of the LVS. 


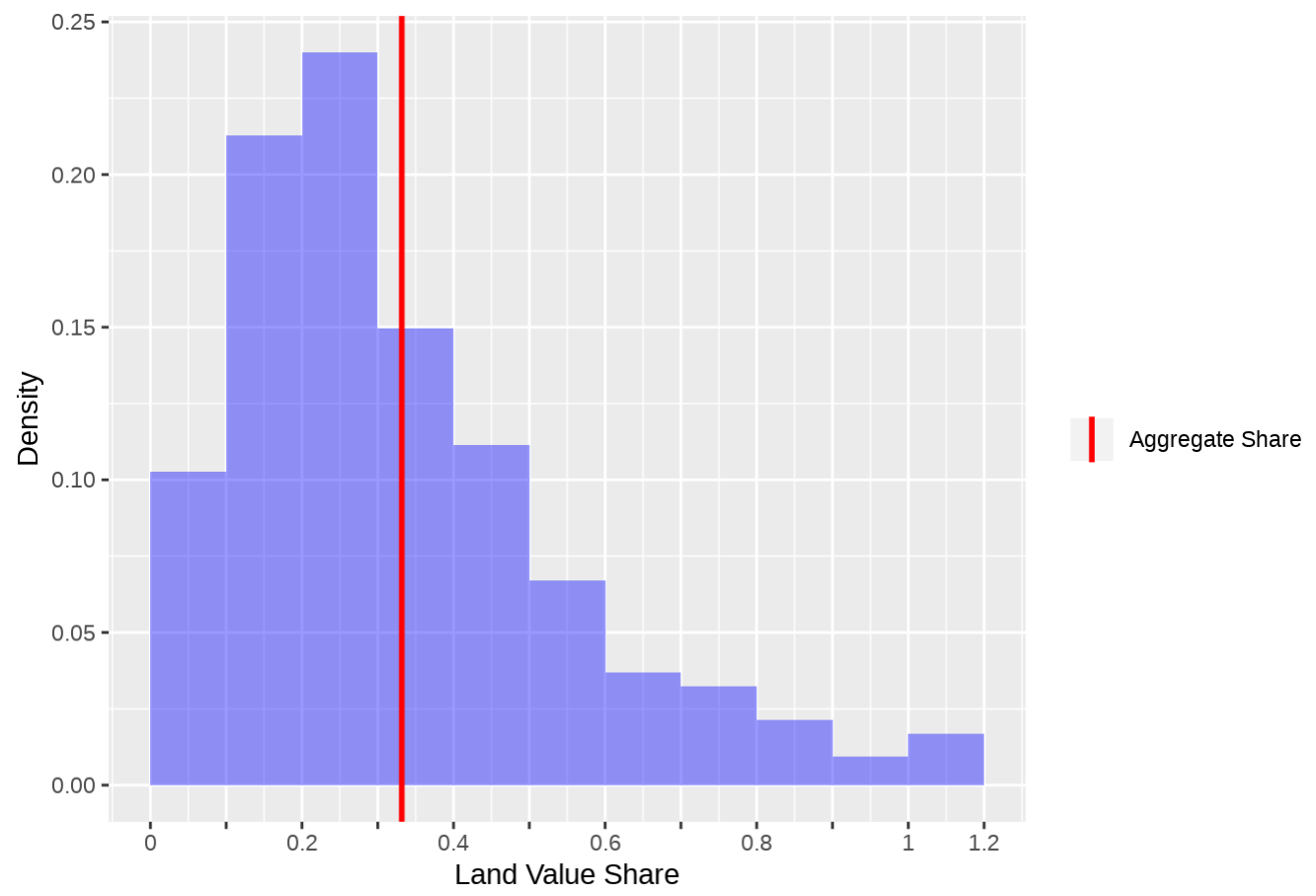

Figure 4: The distribution of land value share

Aggregate share is given by the ratio of total land value to total property value in the sample.

The plot shows the percentage of households in our sample which fall within the bins of LVS we have defined in intervals of 0.1 . The distribution is skewed towards lower values, implying the majority of households lives in houses where land value accounts for a relatively low share of property value. Nevertheless, a significant number of households have high LVS as well, even close to 1 . The plot shows a mass of around $2 \%$ with LVS greater than 1, implying the land is worth more than the property for these observations. While this may appear anomalous, it is entirely possible. A household owning a property which, were it to be sold in the market, would likely imply the demolishing of the existing structures to build new structures, could have a LVS greater than 1 to account for the cost of demolishing.

The vertical line in red depicts the aggregate LVS, meaning the total value of land divided by the total value of property in the sample which can be found in Table 1. This Aggregate LVS (ALVS) will be a centerpiece of the rest of the analysis as it is a crucial threshold defining winners and losers from land value taxation with respect to property value taxation. To understand this, we turn to some simple algebra.

To raise some exogenous level of revenue $\overline{T R}$, the government can choose to either tax land values at a rate $\tau_{L}$ or property values at a rate $\tau_{P}$, such that $\tau_{L} \overline{L V}=\overline{T R}$ or $\tau_{P} \overline{P V}=\overline{T R}$. This means the ratio of the potential tax rates must satisfy

$$
\frac{\tau_{P}}{\tau_{L}}=\frac{\overline{L V}}{\overline{P V}}
$$

At the same time, a household $i$ will pay lower taxes under LVT if $\tau_{L} L V_{i}<\tau_{P} P V_{i}$. Rearranging and substituting the ratio of tax rates by the ratio of aggregates we get the following condition for a lower tax 
burden under a LVT

$$
\underbrace{\frac{L V_{i}}{P V_{i}}}_{\mathrm{LVS}_{i}}<\frac{\tau_{P}}{\tau_{L}}=\underbrace{\frac{\overline{L V}}{\overline{P V}}}_{\mathrm{ALVS}}
$$

Households for which $\operatorname{LVS}_{i}<\operatorname{ALVS}$ (to the left of the red vertical line in Figure 4) will pay less tax under a LVT, those for which $\operatorname{LVS}_{i}>$ ALVS (to the right) will pay more. More concretely, this simple result means that if a household owns, for example, a property worth $300.000 €$ with a land value of $150.000 €$, its land value share is 0.5, higher than the ALVS of 0.33. Despite its tax base is only half under a LVT, the household would still pay more, since the levied tax rate has tripled to guarantee revenue-neutrality.

The analysis of the distribution of the LVS reveals that the decision between a LVT or a property tax can create large differences in tax burdens under the different regimes for a substantial number of households. Next, we investigate how our measure of LVS differs with respect to our main characteristic of interest, income.

\subsection{Land Value Share and Income}

In Figure 5 we see the scatterplot and boxplots of LVS against income and quintiles of income respectively. Also in both plots is the aggregate LVS (in red), separating winners and losers of an LVT. Households below the red line are winners and those above are losers. We see a weak relation between the two. Applying a non-linear trend line reveals the existence of a flat U-shape relation, implying a slight regressive tendency for low income which flips into a slight progressive tendency for higher levels of income.
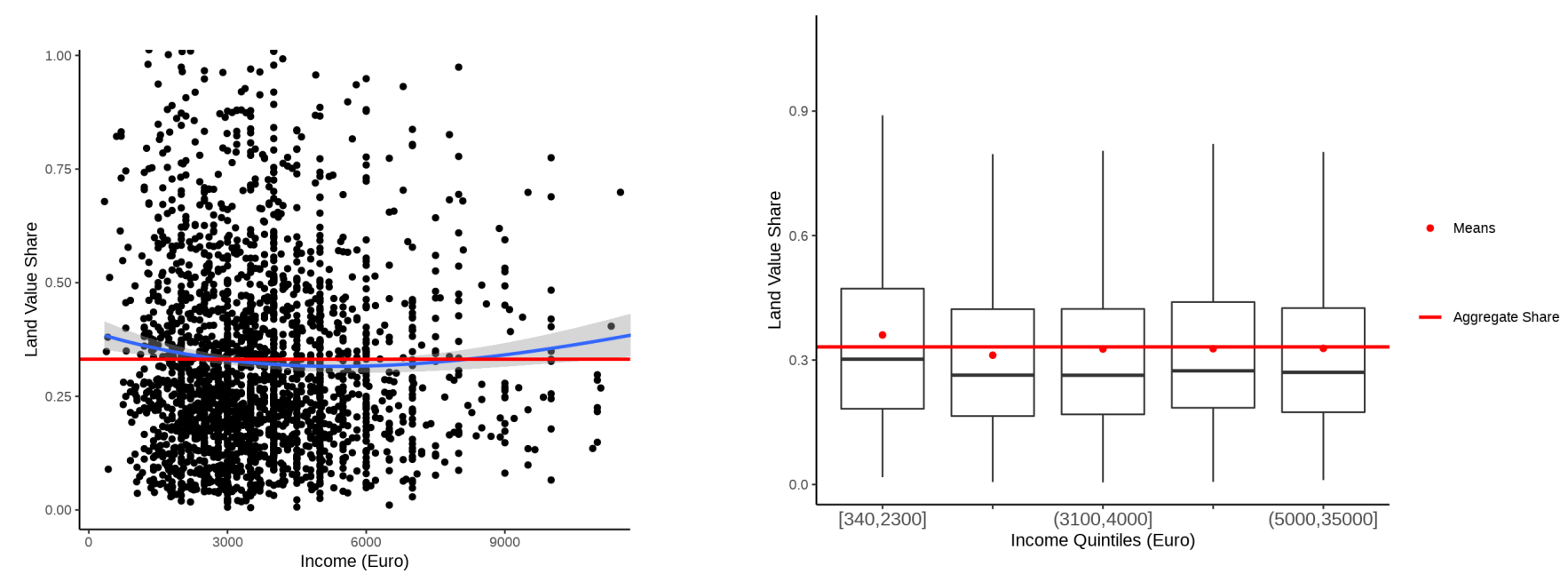

Figure 5: Land value share and income Income is given as monthly income.

Running a simple OLS regression of the LVS on income proves the weak relation as the coefficient on income is not statistically different from zero. It is important to remember this does not mean LVT is not progressive in itself, only that it is not significantly more or less progressive than a tax on property values. Indeed, a simple regression of land value on income shows a very significantly positive coefficient indicating an increase of $1.000 €$ in monthly income is associated with an average increase of land value of $14.000 €$ in our sample. 
A weak relation between LVS and income might be surprising, given the previous result showing land values are more concentrated in our sample than property values. An explanation for this would be that, while land is more concentrated, it is less correlated with income than property values. To investigate this hypothesis, we use Figure6.

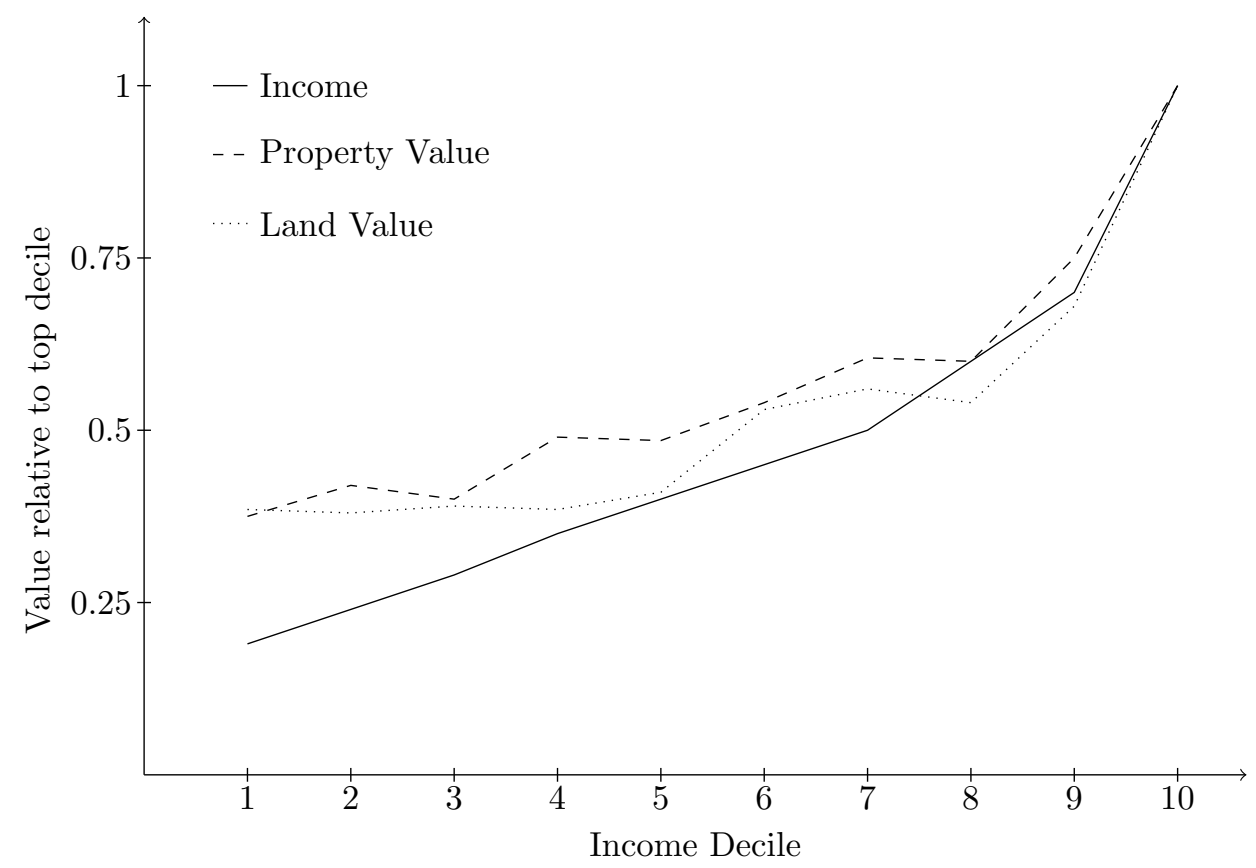

Figure 6: Distribution of income, land value and property value The graph depicts the decile averages, relative to the value of the 10th decile.

Figure 6 represents how much each income decile holds in average income, land and property value with respect to the holdings of the highest income decile. To exemplify, the plot shows the ninth decile of income on average earns roughly between 60 and $65 \%$ of the average earnings in the tenth decile, while holding close to $70 \%$ of the value of the property holdings and close to $60 \%$ of the value of land holdings. Again, this points to a higher concentration of land values relative to property values. But the most interesting aspect of this plot is how the relative distribution of land values is basically flat for the first five deciles of income. While the fifth income decile earns on average twice as much as the lowest, both have similar levels of land holdings on average. On the other hand, distribution of relative property values exhibits some positive correlation with income even for low income levels. This pattern helps in explaining the flat U-shape found in the relation between LVS and income. For low levels of income, property is a better proxy for income than land, and thus taxing property is slightly more progressive, but in the highest deciles, land is more concentrated than property, so a tax on land values is more progressive as, on average, it hurts top income earners more than a property tax.

\subsection{Regional analysis}

So far we have been comparing the progressivity of a LVT and a property tax implicitly assuming all households in our sample would be subject to the same rate of each tax no matter where they live, similarly to what would happen if these taxes were levied at a federal level in Germany. However, property taxation is not carried out at a federal, but regional level, more specifically at a municipality (Gemeinde) level. For this reason, it is necessary 
to tailor our analysis accordingly.

Switching from a federal to a regional level analysis poses challenges. Our previous implicit ratio of tax rates was determined by the aggregate land value share in the sample, which is representative on a federal level. Ideally, we would like to do the same at a municipality level, however, for most municipalities we do not have the sufficient number of observations in the sample to reach a meaningful number. As a consequence, working with such a narrow geographical partition is not an option. Instead, we opt to pool municipalities with similar land values by splitting the observations into five quintiles of average municipal land values, in the hope of capturing most of the relevant structural differences. This way, our highest quintile will be comprised mostly of municipalities with the highest average land value (large cities such as Berlin, Hamburg, Düsseldorf, etc.), while the lowest quintile will be comprised of mostly rural municipalities, capturing most of the diverging characteristics of different municipalities. Figure 7 shows a couple of important structural differences across the average land value quintiles. Henceforth, for ease of exposition, these average land value quintiles will be referred simply as land value regions.

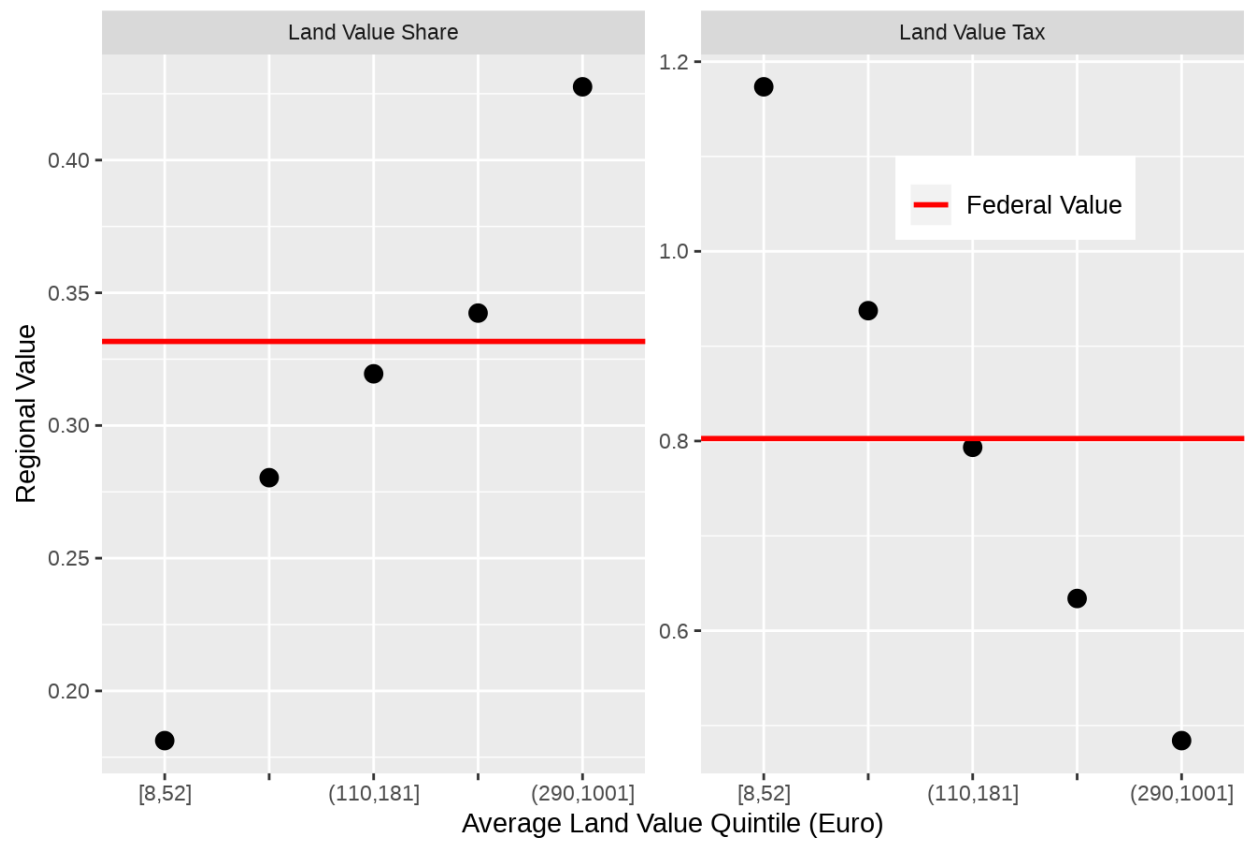

Figure 7: Regional Differences

Panel on the left shows aggregate land value shares computed within each average municipality land value quintile. Panel on the left shows the average revenue neutral land value tax rates within each average municipality land value quintile.

The left panel in Figure 7 shows the aggregate land value share previously discussed at a full sample level (red line), now also computed within each region (black dots). Highest land value region has an aggregate LVS of over 0.45 , around $40 \%$ higher than the full sample (0.33), and almost three times higher than for the region with lowest average land values (0.16). These differences are decisive for our analysis. A household living in the highest land value region with an individual LVS of 0.4 would be a loser from a LVT implemented at a federal level (as it is above the threshold of 0.33), but would be a winner from a LVT implemented at a regional level (as it is below the relevant threshold of 0.45 ).

The right panel in Figure 7 shows the heterogeneity of revenue neutral LVT rates across regions. In line with 
the results in the section on regional differences, regions with higher average land value exhibit lower revenue neutral LVT rates. The highest of the five land value regions has on average a revenue neutral LVT rate below $0.4 \%$, while for the lowest, this number is over $0.8 \%$.

The heterogeneity in regional aggregate land value shares and tax rates indicates there is scope for substantial changes when moving from a federal to a regional analysis. This can be confirmed by a boxplot of LVS across the five land value regions, as seen in Figure 8

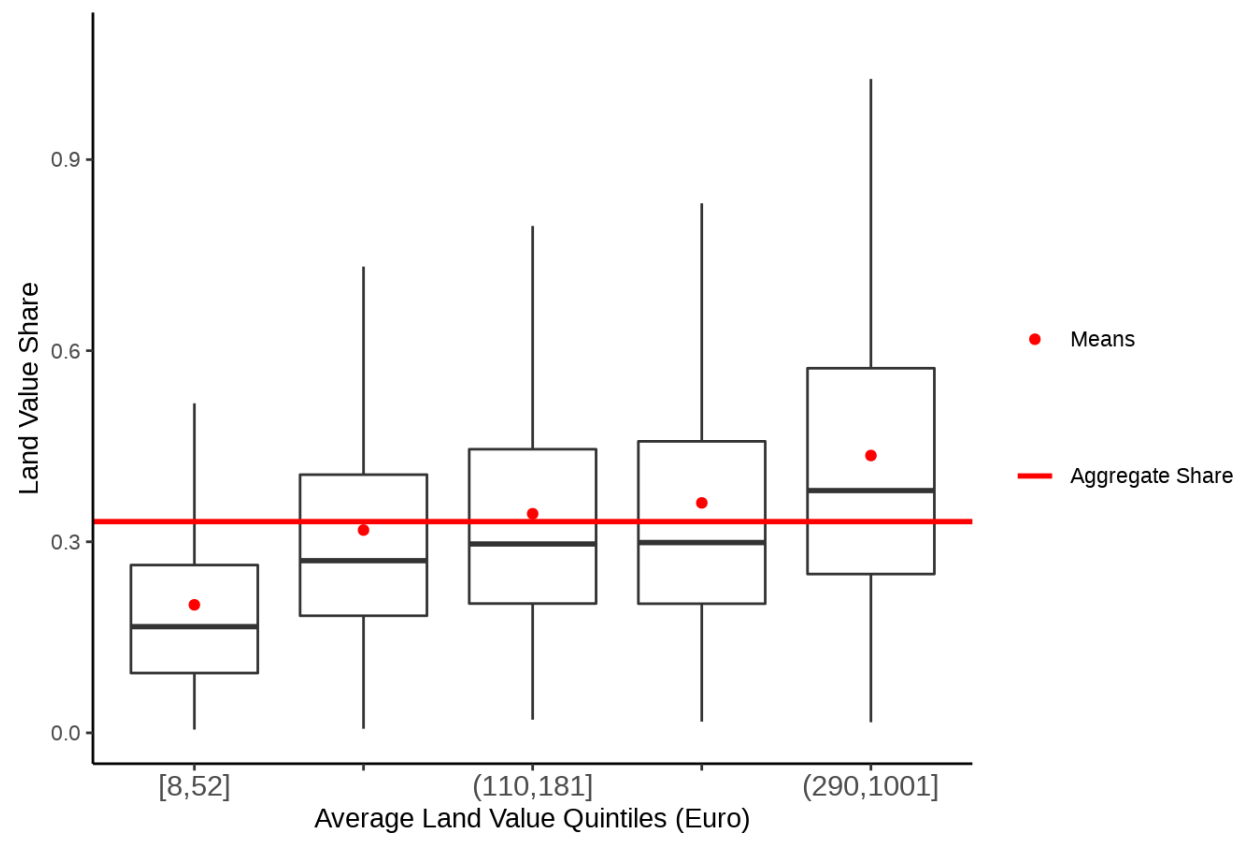

Figure 8: Land value share by average land value

Indeed, Figure 8 reveals stark differences between the two approaches. Using the full sample aggregate LVS (red line) as the threshold to identify winners and losers, one can see a LVT implemented at federal level would lead to more than $75 \%$ winners in rural areas (low land value regions) while creating a majority of losers in big cities (high land value regions). Forgetting about the red line and focusing instead on the within region aggregate LVS (red dots), one can see a very different picture, especially for the lowest and highest land value regions. The median of the distribution across the five regions (black line in the boxplot) is below its respective aggregate LVS, indicating more than $50 \%$ of households would benefit more from a LVT than a property tax, while with a federal tax the majority of households in cities would lose. Also, the percentage of winners in rural regions is considerably lower, even though more than $50 \%$ still win.

Implementing a LVT with a flat rate at a federal level implies substantial inter-regional transfers, from high land value regions to low land value regions. Overall tax neutrality is achieved, but with the burden falling primarily upon big cities. Implementing a LVT at a regional level naturally shuts down the channel of inter-regional transfers as tax neutrality is achieved also at a regional level.

The differences between federal and regional implementation are driven by the strong effect of regional differences in LVS. A log-log OLS regression of LVS on average municipality land value shows a very positive and significant coefficient. An increase of $1 \%$ in average land value is associated with an increase of $0.3 \%$ of LVS with an $R^{2}$ of $16.4 \%$. 
At this point, it is natural to ask if the regional implementation of taxes has any impact on the relation between income and the LVS which, with federal taxes, was virtually non-existing. This would imply conducting the analysis while conditioning on the average land value. Table 2 shows the results of a log-log regression of LVS on income including the average land value as a control.

\begin{tabular}{lcc}
\hline & $(1)$ & $(2)$ \\
\hline Intercept & $-2.781^{* * *}$ & $-1.599^{* * *}$ \\
& $(0.068)$ & $(0.224)$ \\
Average Land Value & $0.294^{* * *}$ & $0.310^{* * *}$ \\
& $(0.014)$ & $(0.014)$ \\
Income & & $-0.155^{* * *}$ \\
& & $(0.028)$ \\
\hline $\mathrm{N}$ & ------ & ---1359 \\
$R^{2}$ & 2359 & 0.174 \\
adj. $R^{2}$ & 0.164 & 1.174 \\
\hline
\end{tabular}

Table 2: Land value share on income and average land value The table presents the results of log-log OLS regressions. Standard errors in parenthesis.

Results of the regression in Table 2 show that, when controlling for average land value, income has a statistically significant negative impact on LVS. More specifically, an increase of $1 \%$ in income is associated with a decrease of $0.15 \%$ in land value share in our sample of homeowners. However, it should be noted the inclusion of income in the regression from an initial specification with only average land value modestly increases the $R^{2}$, indicating there is a wide dispersion of LVS for households with similar incomes within land value regions and thus that income is not a strong predictor of whether a household will pay more or less under a LVT compared to a property tax.

The change in the coefficient for income after the inclusion of average land value in the regression suggests a positive correlation between income and average land value of the region. In the next section, we will study this relation in greater depth as well as identify all the channels through which income impacts the LVS.

\subsection{Decomposing the Income Elasticity of the Land Value Share}

In this section we lay out a simple analytic framework to decompose the effect of income on the land value share in several intuitive channels. The decomposition sheds light on the origins of the distributional effect and once again accentuates the importance of a regional consideration. We present our results in terms of elasticities and estimate the main parameters using data from SOEP 2.0.

The LVS of household $i$ is given by $L V S_{i}=L V_{i} / P V_{i}$. Accordingly, income has an impact on the LVS through the denominator (land and structures value) and the nominator (land value). Within the scope of our paper, we keep the effect of income on structure value as a whole, but decompose the effect on land value. Mechanically, we can decompose the household's land value into its constituent components according to our 
calculation:

$$
L V_{i}=l v_{i} \frac{\text { lot.size }}{h h_{i}}
$$

$l v_{i}$ denotes the land value per $m^{2}$, lot.size $_{i}$ denotes the size of the lot the house of the household is built and $h h_{i}$ denotes the number of households sharing the lot given by the product of number of addresses and number of neighbours per address. Substituting this expression back into our identity of LVS in logs we get

$$
\log \left(L V S_{i}\right)=\log \left(l v_{i} \frac{\text { lot.size }}{h h_{i}}\right)-\log \left(P V_{i}\right)
$$

We can further break down this identity until we arrive at a linear relation between the logs of these variables.

$$
\log \left(L V S_{i}\right)=\log \left(l v_{i}\right)+\log \left(s i z e_{i}\right)-\log \left(P V_{i}\right)
$$

Here, lot.size $e_{i} / h h_{i}$ was kept as a single variable and renamed size $_{i}$. In a next step, we break down $l v_{i}$ into a regional component which is the average land value of the region $\left(A l v_{i}\right)$ and a factor capturing the deviation from the regional average $\left(R l v_{i}\right)$, which henceforth we denote as relative land value (as in relative to the average of the municipality). So, if household $i$ resides in a lot with a land value per $m^{2}$ of $120 €$, located in a municipality where the average land value per $m^{2}$ is $100 €$, we can rewrite the 120 as $100 \times 1.2$. Applying this decomposition to our LVS expression and once again separating the resulting multiplication inside the log, we arrive at:

$$
\log \left(L V S_{i}\right)=\log \left(A l v_{i}\right)+\log \left(R l v_{i}\right)+\log \left(s i z e_{i}\right)-\log \left(P V_{i}\right)
$$

So far, we have decomposed the land value in three components. We continue by setting up a Structural Equation Model (SEM) to quantify the impact of income on LVS through each of them. In order to determine the full impact of each component, we have to quantify their impact through property value, too. We perform the relevant corrections ex post.

From (1) the income elasticity of the share can be decomposed to:

$$
\frac{\partial \log \left(L V S_{i}\right)}{\partial \log \left(I_{i}\right)}=\frac{\partial \log \left(A l v_{i}\right)}{\partial \log \left(I_{i}\right)}+\frac{\partial \log \left(R l v_{i}\right)}{\partial \log \left(I_{i}\right)}+\frac{\partial \log \left(\text { size }_{i}\right)}{\partial \log \left(I_{i}\right)}-\frac{\partial \log \left(P V_{i}\right)}{\partial \log \left(I_{i}\right)}
$$

The first three terms of (2) are denoted as: Regional Effect (RE), Neighborhood Effect (NE), Size Effect (SE). Broadly, they capture the impact of income on the LVS through: the correlation between the regional price level and income (RE), the decision to live in a neighborhood with a certain level of amenities (NE), the decision to live in a bigger lot and a Single or Multiple Family House (SE). The last term of (2) captures the full impact of income on the LVS through property value and it will be decomposed ex post. Initially, we estimate the individual terms by using the following set of equations in the framework of a SEM:

$$
\begin{array}{lll}
\log \left(\text { Alv }_{i}\right)=\alpha_{1}+\beta_{1} \log \left(I_{i}\right)+\epsilon_{1, i} & (3 \mathrm{a}) & \log \left(\text { Rlv }_{i}\right)=\alpha_{2}+\beta_{2} \log \left(I_{i}\right)+\gamma_{2} \log \left(A l v_{i}\right)+\epsilon_{2, i} \\
\log \left(\text { size }_{i}\right)=\alpha_{3}+\beta_{3} \log \left(I_{i}\right)+\gamma_{3} \log \left(A l v_{i}\right)+\epsilon_{3, i} & \text { (3c) } & \log \left(P V_{i}\right)=\alpha_{4}+\beta_{4} \log \left(I_{i}\right)+\gamma_{4} \log \left(A l v_{i}\right)+\epsilon_{4, i}
\end{array}
$$

In our SEM-framework, it is important to not only incorporate the direct impact through Alv in (3a). In $\left(3 \mathrm{~b}\right.$ the inclusion of $A l v_{i}$ corrects for the fact that in areas with high average land values, mostly cities, 
the highest land values are measured in zones where residential and commercial usages are mixed, e.g. in city centers. Thus, fewer households live in these zones and so, the relative land value in cities is structurally underestimated. In $3 \mathrm{c}$ the inclusion corrects for the fact that in municipalities with high average land value, mostly cities, the average lot size is structurally smaller. Finally, in $3 \mathrm{~d}$ the $A l v_{i}$ is included to control for different levels of construction costs in cities versus villages.

Using the results of the SEM in (2), the average elasticity is given by:

$$
\frac{\partial \log (L V S)}{\partial \log (I)}=\left(1+\gamma_{2}+\gamma_{3}-\gamma_{4}\right) \beta_{1}+\beta_{2}+\beta_{3}-\beta_{4}
$$

The effect through property value, $\beta_{4}$, still carries the effect through land and structure value. We decompose the effect in a structure value effect $\beta_{5}$ and the different land value effects, using the identity $P V_{i}=S V_{i}+L V_{i}$. After some reformulations the structure value effect is given by:

$$
\beta_{5}=\overline{\left(\frac{P V_{i}}{S V_{i}}\right)}\left(\beta_{4}+\gamma_{4} \beta_{1}\right)-\overline{\left(\frac{L V_{i}}{S V_{i}}\right)}\left(\left(1+\gamma_{2}+\gamma_{3}\right) \beta_{1}+\beta_{2}+\beta_{3}\right)
$$

Using the results in (4), the income elasticity of the LVS finally reads:

$$
\frac{\partial \log (L V S)}{\partial \log (I)}=\underbrace{\overline{\left(\frac{S V_{i}}{P V_{i}}\right)}\left(1+\gamma_{2}+\gamma_{3}\right) \beta_{1}}_{\mathrm{RE}}+\underbrace{\overline{\left(\frac{S V_{i}}{P V_{i}}\right)} \beta_{2}}_{\mathrm{NE}}+\underbrace{\overline{\left(\frac{S V_{i}}{P V_{i}}\right)} \beta_{3}}_{\mathrm{SE}}-\underbrace{\overline{\left(\frac{S V_{i}}{P V_{i}}\right) \beta_{5}}}_{\mathrm{HE}}
$$

The intuition of the first three terms was introduced before. Their magnitude is now corrected for presence in denominator and nominator. The fourth effect is denoted as House Effect (HE). It captures the impact of income on the LVS through the decision to invest in the structure value, by renovation or buildup.

The Regional Effect is a special case in two ways. First, due to simultaneity, the Regional Effect cannot be interpreted causally. Only households with a sufficiently high income can afford to live in cities and surrounding municipalities given the soaring land prices over the last years. However, at the same time, firms in cities tend to pay higher wages in order to compensate for the higher living costs in these areas. Second, as argued in the previous sections, the Regional Effect is irrelevant for a distributional assessment as property taxes are collected on a municipal level.

Our preferred interpretation of the income elasticity of the LVS is the sum of NE, SE and HE, the (regional) net elasticity. However, to accentuate the importance of the regional component and to hinge our analysis to previous sections, we run the full model and present gross and net elasticity separately.

Figure 9 shows the results of our decomposition of the income elasticity of the LVS through a structural equation model. Given the identity-based approach of this section, the estimates of the full elasticities (Gross Elasticity, Net Elasticity) match the results of the log-log OLS regressions of LVS on income previously presented. The gross income elasticity of LVS is not statistically different from zero, while after filtering out the Regional Effect the net income elasticity is -0.15 , significantly different from zero.

\footnotetext{
${ }^{6}$ The reformulation procedure is summarized in Appendix B.
} 


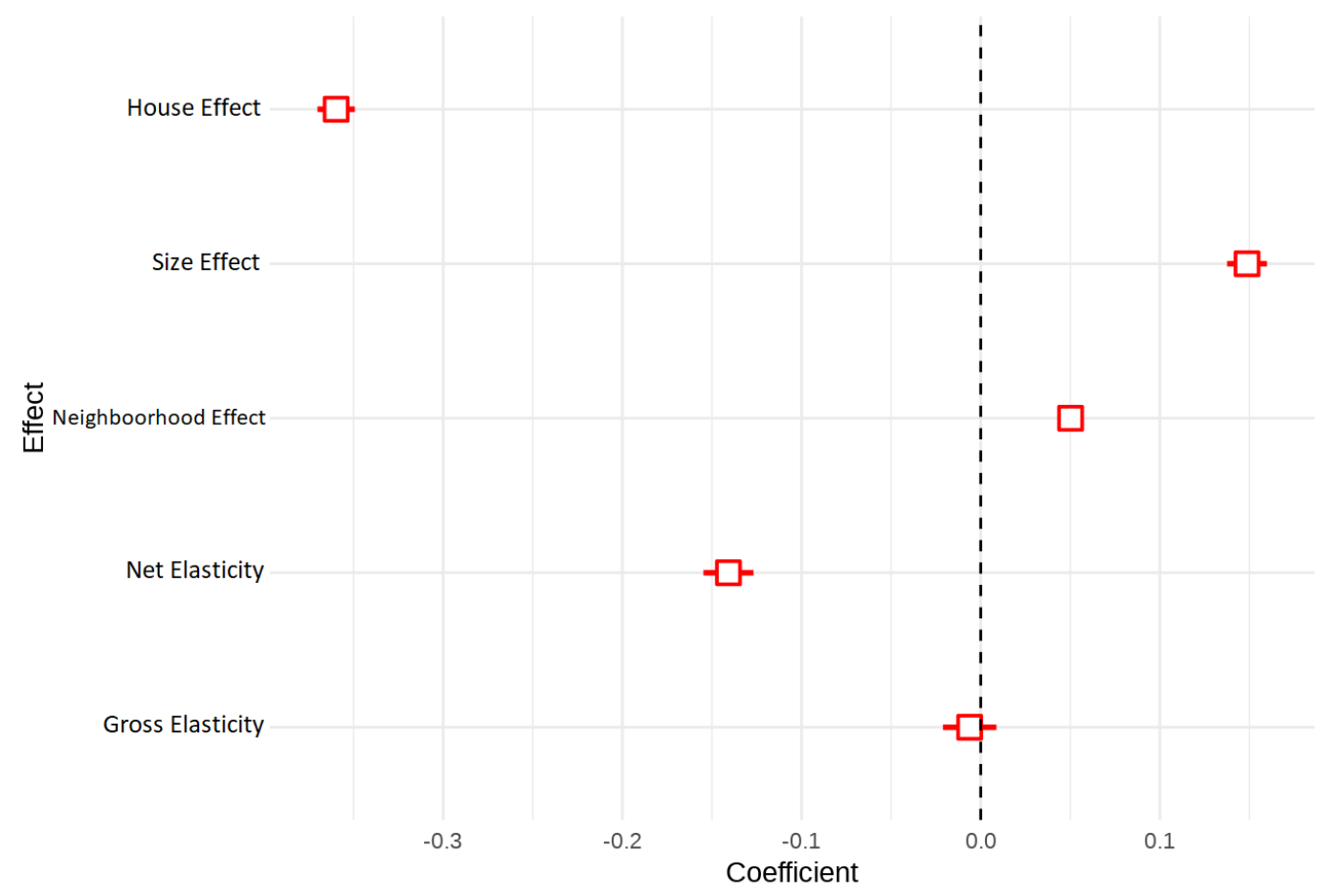

Figure 9: Decomposition of the income elasticity of the land value share.

Gross effect includes effect of income through average land value effect (region effect). Net effect excludes this channel.

We interpret the net effect and its components. The House Effect is close to -0.36, dominating Neighborhood and Size Effect, which are at 0.15 and 0.05 . The reason is that structure value is easier to adjust than land value. Changing the land value by altering the lot size is oftentimes not feasible due to physical constraints, changing the land value by moving to a different neighborhood triggers moving costs. In general, the argument applies independent of the direction of adjustment. However, in particular for the Neighborhood Effect we find an accentuated downward rigidity. This means although it is difficult to find high income households in low land value neighbourhoods, it is not uncommon to find low income households in high land value neighbourhoods.

In sum, this section shows that on average households with higher income: occupy larger lots, live in more expensive areas, invest more in renovation and buildup of their houses. Comparing the magnitudes, our analysis reveals that the house margin is the dominant one. Thus property value is a better 'tag' for income than land value, making a Land Value Tax less progressive than a property tax within regions. Finally, to capture this relation it is important to remove the regional veil.

\subsection{Quantitative analysis}

So far, we have focused our analysis around land value share as a sufficient statistic to determine who wins and loses from a LVT compared to a property tax. However, the LVS hides an important dimension: the magnitude of the change in tax burden. Distance of a household's LVS from the aggregate LVS is not an accurate measure of how much a specific household will be affected. Take two households with the same LVS, which is higher than the aggregate LVS, but where one has values of land and property which are half of the other. Clearly, the household with the highest underlying value of assets stands to lose more from a LVT.

Table 3 summarizes the quantitative impact of a LVT for the different income quintiles. 


\begin{tabular}{|c|c|c|c|c|c|}
\hline & \multicolumn{5}{|c|}{ Income Quintile } \\
\hline & 1 & 2 & 3 & 4 & 5 \\
\hline Percentage of losers in $\%$ & 54.2 & 44.8 & 44.1 & 42.2 & 37.2 \\
\hline Mean & 39.64 & 2.80 & 9.89 & -6.64 & -49.98 \\
\hline 1st Quartile & -78.46 & -128.23 & -142.79 & -159.81 & -238.57 \\
\hline Median & 21.18 & -19.66 & -30.45 & -46.34 & -78.26 \\
\hline 3rd Quartile & 143.72 & 102.13 & 131.10 & 128.39 & 109.95 \\
\hline
\end{tabular}

Table 3: Winners and losers of a LVT (I)

The values are computed as the difference between LVT and property tax burden. Positive values indicate higher burden under a LVT.

In general, average LVT burdens range from around $300 €$ for the lowest income quintile to around $650 €$ for the highest. Regarding winners and losers, Table 3 picks up the regressive trend we have encountered in previous sections. While over half of the households in the lowest quintile pay more under LVT, this number is $37.2 \%$ for the highest income quintile. On the quantitative dimension, the results show that implementing a LVT decreases the difference in the average tax burden between first and fifth income quintile by around $90 €$.

The quantitative results prove the intuition of our qualitative section, however, the effects turn out to be modest in magnitude. The reason is the traditionally low level of property taxation in Germany. In particular, the revenue neutral land value tax rates have a mean of $0.6 \%$.

The significance of property taxes however has recently risen in Germany. Over the last years, tax rates have increased nationwide. Furthermore, in other countries, property taxation is a much more important source of revenue. Thus, in a next step we provide statistics to show our results potentially will have significant quantitative impact, if the importance of property taxation continues to rise.

In particular, we compute the variation in tax burden as a percentage of the value of one of the tax burdens in order to make it invariant to the scale of the total revenues being raised. This way one can say, for example, household $i$ will pay 30\% more under a LVT compared to a property tax. The corresponding monetary burdens depend on the magnitude of the tax rates, but the ratio between the tax burdens would remain unaffected. The results of such analysis are shown in Table 4 , again broken into income quintiles.

\begin{tabular}{|c|c|c|c|c|c|}
\hline & \multicolumn{5}{|c|}{ Income Quintile } \\
\hline & 1 & 2 & 3 & 4 & 5 \\
\hline Percentage of losers in \% of Sample & 54.2 & 44.8 & 44.1 & 42.2 & 37.2 \\
\hline in $\%$ of PT Burden & 24.49 & 6.31 & 8.16 & 3.88 & -4.17 \\
\hline 1st Quartile & -34.46 & -40.97 & -39.76 & -40.33 & -44.62 \\
\hline Median & 8.01 & -8.47 & -8.31 & -12.24 & -18.60 \\
\hline 3rd Quartile & 64.50 & 36.05 & 38.51 & 37.66 & 22.33 \\
\hline
\end{tabular}

Table 4: Winners and losers of a LVT (II)

The values are computed as the difference between LVT and property tax burden, relative to the property tax burden. Positive values indicate higher burden under LVT. 
Table 4 shows considerable differences in tax burdens. The average change in tax burden for the lowest income quintile is $24.49 \%$, meaning households in this quintile would pay, on average, $24.49 \%$ more under a LVT than under a property tax regime. For other quintiles, average changes are below 10\%. However, the numbers are substantially higher when looking beyond the mean. For more than half of the households in the sample, their burdens change at least $22 \%$ under the two different regimes. A quarter of households in the lowest income quintile would pay at least $65 \%$ more under a LVT, while another quarter would pay at least $35 \%$ less. This analysis confirms our initial assessment that the high dispersion in LVS can lead to significant differences in tax burdens across households.

The data also allows us to investigate in which average land value regions the biggest winners and losers reside. Although one might think the differences would be greater in the highest land value regions, we find the scope and magnitude of the change to be relatively similar across regions.

It is relevant to notice the median voter in our sample of homeowners would be for the implementation of the LVT. A result that holds also within each of the five land value regions we consider. The result that median household pays less under a LVT is a consequence of the higher concentration of land values in our sample of homeowners, leading to a greater share of the total tax burden being paid by fewer households.

\section{Current Property Taxation}

In Germany the current system of property taxation assesses a household's property tax burden based on property values from 1964 in West- and 1935 in East-Germany. Property values have not been updated subsequently due to the bureaucratic costs of a regular assessment. The outdated property values led the German constitutional court to rule out the current property tax regime in 2018.

In our main analysis we have discussed the distributional consequences of a land value tax as compared to a property tax based on actual property values (NPT). This section complements the analysis by evaluating the distributional consequences of a LVT as compared to the current system of property taxation (CPT). Both type of analyses have attractive features. On the one hand, LVT and NPT are the only realistic options for property taxation in the future. So, a distributional assessment helps to decide on the preferable policy option. On the other hand, for the German case, a comparison of LVT and CPT determines the realized change in tax burden of a LVT, when moving away from the current system of property taxation.

We do not have information on the historic property values used as the tax base in CPT, however, the SOEP contains information on the CPT burden directly. Compared to actual property values, two features of CPT become visible. First, the tax burden increases in the actual property value, as depicted in the left panel of Figure 10. Despite the outdated assessment, CPT captures the differences in property values to a certain extent. Second, the effective average CPT rate decreases in the actual property value, as depicted in the right panel of Figure 10. Compared to the actual property value, CPT is regressive in nature. 


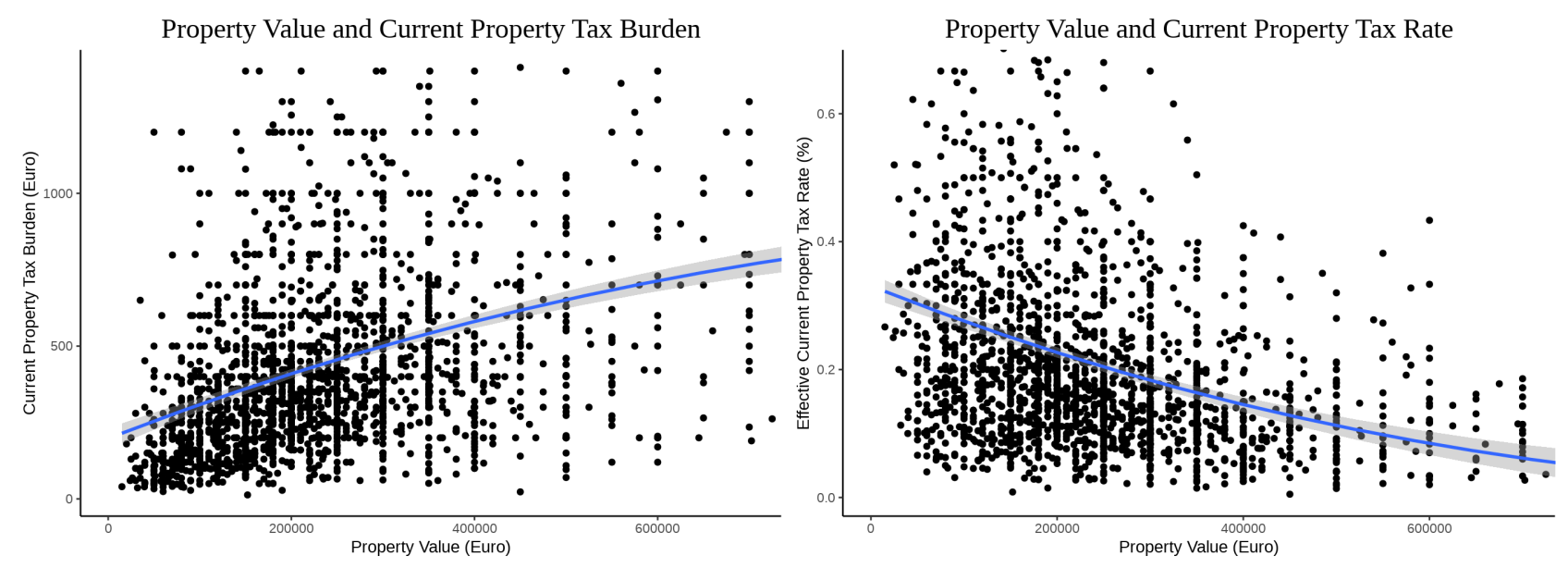

Figure 10: Current property tax system

The panels depict the level of current property tax burden (left) and the effective average current property tax rate (right).

Given the historic tax base assessment, CPT is incapable to equalize tax rates on property values, which have diverged since the last assessment in 1964, or 1935 respectively. The main driver for divergence during that period are land values. Differences in the growth rate of land values across municipalities are balanced out by different growth rates in tax rates. However, differences in the growth rate of land values within a municipality necessarily lead to a divergence in effective tax rates. In particular, the effective average tax rate for property values with a relatively high land value is structurally lower under CPT. As most of the high value properties are located in such land value zones, CPT is regressive with respect to actual property values.

Since high value properties are predominantly owned by households with a high income, in isolation, the inability of the current property tax system to equalize effective tax rates on properties across different land value zones within a municipality makes CPT less progressive than a LVT. However, CPT takes into account characteristics of the structures to assess a household's tax burden, which, as argued in our main analysis, makes a LVT less progressive. In total, the mitigation of relative land values in CPT dominates, so that a change from CPT to a LVT would shift tax burden from low to high income quintiles, as depicted in Figure 11. 


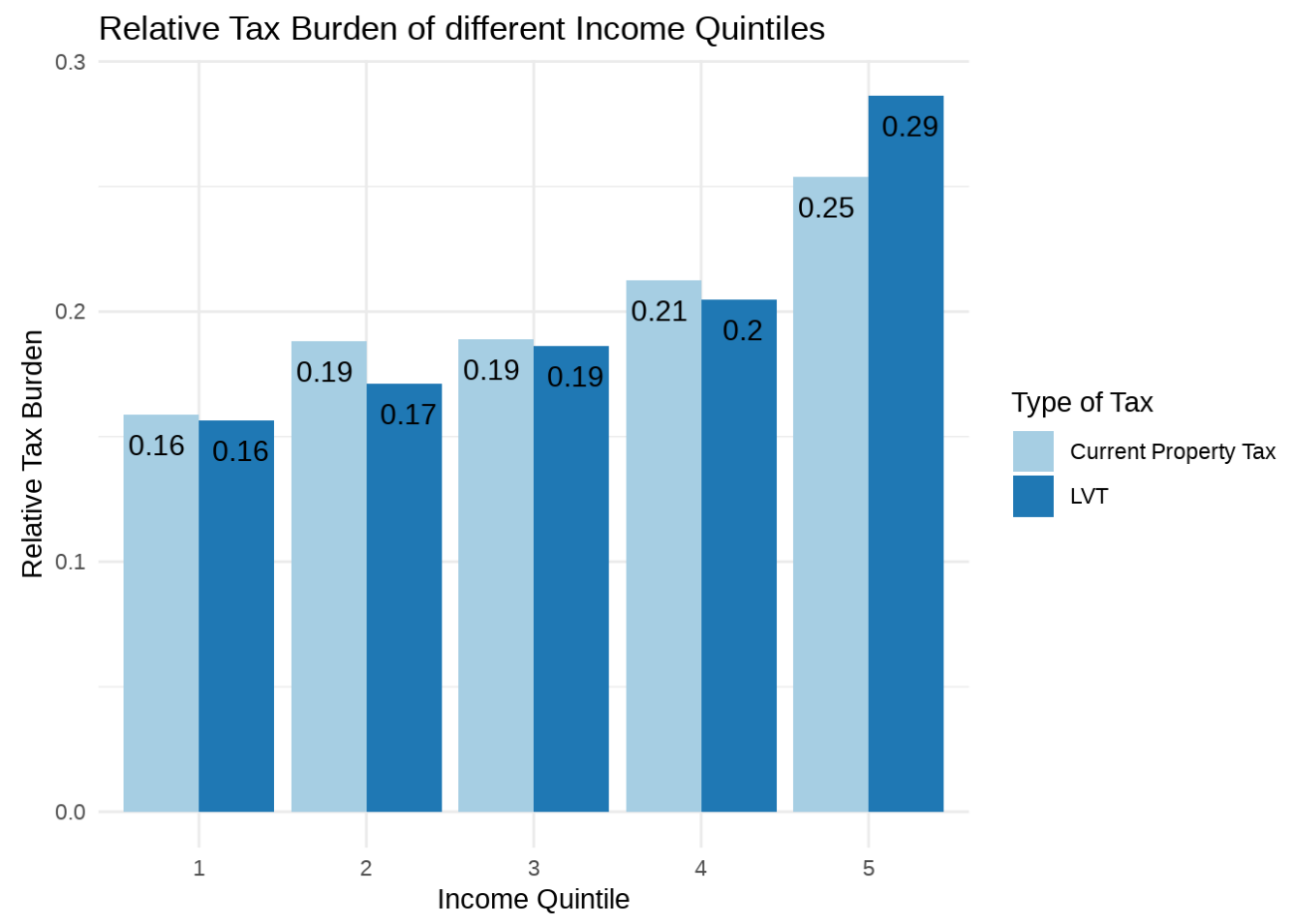

Figure 11: Distributional impact of a LVT compared to the current property tax

The figure depicts the fraction of tax burden carried by the respective income quintiles under the different tax regimes. The land value tax rates are chosen to guarantee budget-neutrality for the sample as a whole.

\section{Conclusion}

This paper sets out to provide the first empirical identification of the distribution of property and land values at a household level and their relation to income. Those statistics are used to study the distributional consequences of implementing land value taxation compared to standard property taxation. Land value taxation offers various theoretical advantages over property taxation, but the distributional consequences at a household level remained unknown, making its implementation hard to justify. Using geographical matching, official land values and lot data for five German states we successfully estimate the land value associated with the household's primary property value for a sample of close to 2400 homeowners in the German household survey for 2017.

At a municipal level we find revenue neutral property tax rates on average around $0.6 \%$, with considerable regional differences (lower rates the more densely populated). We find the aggregate level of land value to be substantially high, around 1.2 times GDP for the whole region.

At a household level we find considerable heterogeneity in the relative distributions of land and property with an average value of $33 \%$ for the share of land value to property value, which was shown to be a sufficient statistic to determine winners and losers from a switch to LVT. We also find no distributional impact from a switch to LVT at a federal implementation level, but a significant regressive impact at a regional level. Given that property taxation has traditionally been a regional tax, the regressive result is our preferred one.

However, the quantitative impact in our sample is modest. Implementing a LVT would decrease the difference of tax burden between the first and fifth income quintile by no more than $100 €$ annually. This result is due 
to the traditionally low level of property taxation in Germany. If we set the change in respect to current tax burdens, we find that households of the first income quintile experience an increase of around $25 \%$ on average. Thus, in times of rising property tax rates, our results will have an important implication for future policy debates.

Looking ahead, if recent trends of increased gentrification continue, it might lead to an allocation of households across land value areas more in line with household income, making LVT more naturally progressive than property value tax. Regardless, both are likely to produce winners and losers across all income classes, creating the need for careful implementation. This can be accomplished, for example, through exemptions, phase-in periods or the implementation of complementary policies targeted at low income households.

Yet, our results focus solely on primary residences of homeowners. The effect of a switch in the tax regime on renters and landlords critically depends on the incidence of the tax. Standard economic theory suggests a tax on land values would not be passed onto renters, due to the inelastic nature of land supply, making them winners of a LVT. However, in Germany property taxes are traditionally part of the utilities, so that, at least on impact, a part of the change in burden might be passed through to renters. In principle, our data would allow us to incorporate the effects on renters as well. However, such analysis would require additional assumptions on the rent to property value ratio. In order to generate cleaner results, we left renters out of this project. The inclusion of them is an interesting future extension of this project.

This paper focuses solely on the on-impact distributional effects of different types of property taxation, ignoring dynamic general equilibrium effects. If the theoretical benefits of implementing a LVT are realized, namely through higher housing investment, and subsequent control of inflationary pressures on rents, for example, the benefits may outweigh the costs. The construction of a theoretical model which includes these effects is an obvious path for future research on this topic. 


\section{References}

Aura, S. and Davidoff, T. (2012). An Analysis of Constrained Property Taxes in a Simple Optimal Tax Model. CESifo Economic Studies, 58(3):525-543.

England, R. W. and Zhao, M. Q. (2005). Assessing the Distributive Impact of a Revenue-Neutral Shift From a Uniform Property Tax to a Two-Rate Property Tax With a Uniform Credit. National Tax Journal, 58(2):247260 .

Fuest, C., Immel, L., Meier, V., and Neumeier, F. (2018). Reformoptionen für die Grundsteuer B: Eine empirische Analyse der Belastungswirkungen. ifo Schnelldienst, 71(22):23-29.

Larson, W. (2015). New Estimates of Value of Land of the United States. BEA Working Papers 0120, Bureau of Economic Analysis.

Mirrlees, J., Adam, S., Besley, T., Blundell, R., Bond, S., Chote, R., Gammie, M., Johnson, P., Myles, G., and Poterba, J. (2011). The mirrlees review: Conclusions and recommendations for reform. Fiscal Studies, $32(3): 331-359$.

Oates, W. and Schwab, R. M. (1997). The impact of urban land taxation: The pittsburgh experience. National Tax Journal, 50(1):1-21.

Plummer, E. (2010). Evidence on the distributional effects of a land value tax on residential households. National Tax Journal, 63(1):63-92.

Rognlie, M. (2015). Deciphering the fall and rise in the net capital share. Brookings Papers on Economic Activity, 46(1 (Spring)):1-69.

Stiglitz, J. E. (2015). New Theoretical Perspectives on the Distribution of Income and Wealth among Individuals: Part II: Equilibrium Wealth Distributions. NBER Working Papers 21190, National Bureau of Economic Research, Inc. 


\section{A Construction of SOEP 2.0}

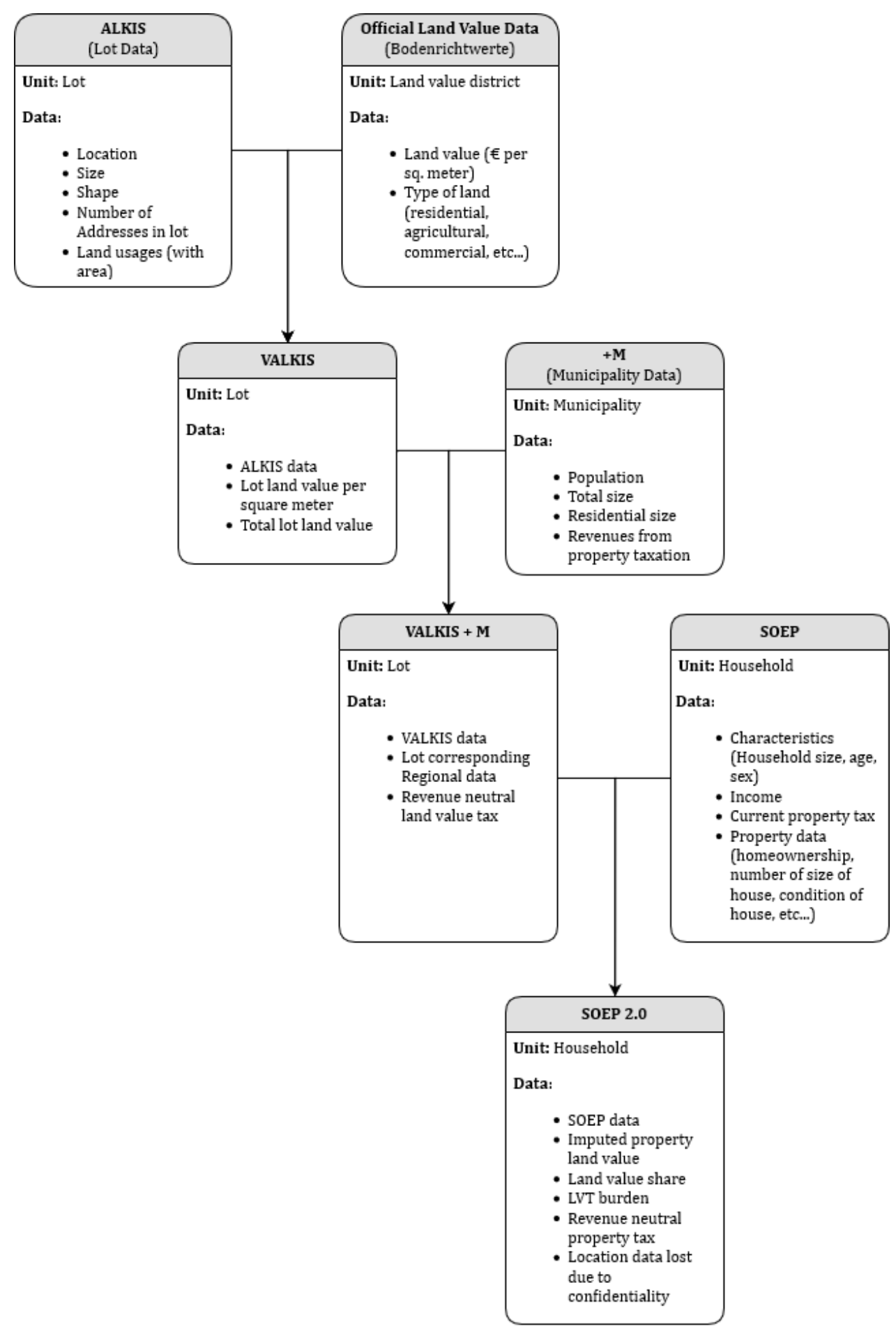

Figure 12: Data flowchart

\section{B Decomposing the Income Elasticity of the Land Value Share}

Given the construction of Land Value and Property Value, the following equation holds by identity:

$$
\log (\mathrm{LVS})=\log (\mathrm{Alv})+\log (\mathrm{Rlv})+\log (\operatorname{size})-\log (\mathrm{PV})
$$


See that throughout the presentation of the results, we drop the subscripts to ease the exposition.

Accordingly, the income elasticity of the Land Value Share is given by:

$$
\frac{\partial \log \mathrm{LVS}}{\partial \log \mathrm{I}}=\frac{\partial \log \mathrm{Alv}}{\partial \log \mathrm{I}}+\frac{\partial \log \mathrm{Rlv}}{\partial \log \mathrm{I}}+\frac{\partial \log \operatorname{size}}{\partial \log \mathrm{I}}-\frac{\partial \log \mathrm{PV}}{\partial \log \mathrm{I}}
$$

We can use the results of the regressions (3a) to $(3 \mathrm{~d})$ in order to reformulate:

$$
\frac{\partial \log \mathrm{LVS}}{\partial \log \mathrm{I}}=\beta_{1}+\left(\beta_{2}+\gamma_{2} \frac{\partial \log \mathrm{Alv}}{\partial \log \mathrm{I}}\right)+\left(\beta_{3}+\gamma_{3} \frac{\partial \log \mathrm{Alv}}{\partial \log \mathrm{I}}\right)-\left(\beta_{4}+\gamma_{4} \frac{\partial \log \mathrm{Alv}}{\partial \log \mathrm{I}}\right)
$$

Once again using the result from regression $3 \mathrm{a}$ that $\frac{\partial \log \mathrm{Alv}}{\partial \log \mathrm{I}}=\beta_{1}$, we arrive at:

$$
\frac{\partial \log \mathrm{LVS}}{\partial \log \mathrm{I}}=\left(1+\gamma_{2}+\gamma_{3}-\gamma_{4}\right) \beta_{1}+\beta_{2}+\beta_{3}-\beta_{4}
$$

In a next step, we want to decompose the income elasticity of property values in parts, regarding the income elasticity of land value (LV) and structures value (SV). The steps are:

$$
\frac{\partial \log \mathrm{PV}}{\partial \log \mathrm{I}}=\frac{\frac{\partial \mathrm{PV}}{\partial \log \mathrm{I}}}{\mathrm{PV}}=\frac{\frac{\partial(\mathrm{SV}+\mathrm{LV})}{\partial \log \mathrm{I}}}{\mathrm{PV}}=\frac{\mathrm{SV}}{\mathrm{PV}} \frac{\frac{\partial \mathrm{SV}}{\partial \log \mathrm{I}}}{\mathrm{SV}}+\frac{\mathrm{LV}}{\mathrm{PV}} \frac{\frac{\partial \mathrm{LV}}{\partial \log \mathrm{I}}}{\mathrm{LV}}=\frac{\mathrm{SV}}{\mathrm{PV}} \frac{\partial \log \mathrm{SV}}{\partial \log \mathrm{I}}+\frac{\mathrm{LV}}{\mathrm{PV}} \frac{\partial \log \mathrm{LV}}{\partial \log \mathrm{I}}
$$

Now, define the income elasticity of structures, such that $\beta_{5} \equiv \frac{\partial \log \mathrm{SV}}{\partial \log \mathrm{I}}$. Furthermore, by our identities it holds that $\frac{\partial \log L V}{\partial \log I}=\frac{\partial \log A l v}{\partial \log I}+\frac{\partial \log R l v}{\partial \log I}+\frac{\partial \log \operatorname{size}}{\partial \log I}$. Using the definitions and the results from (3a) - (3c), we can reformulate:

$$
\frac{\partial \log \mathrm{PV}}{\partial \log \mathrm{I}}=\frac{\mathrm{SV}}{\mathrm{PV}} \beta_{5}+\frac{\mathrm{LV}}{\mathrm{PV}}\left(\left(1+\gamma_{2}+\gamma_{3}\right) \beta_{1}+\beta_{2}+\beta_{3}\right)
$$

Finally, from $3 \mathrm{~d}$ we also know that it holds that $\frac{\partial \log \mathrm{PV}}{\partial \log \mathrm{I}}=\beta_{4}+\gamma_{4} \beta_{1}$. Putting the equations together, we derive:

$$
\beta_{4}=\frac{\mathrm{SV}}{\mathrm{PV}} \beta_{5}+\frac{\mathrm{LV}}{\mathrm{PV}}\left(\left(1+\gamma_{2}+\gamma_{3}\right) \beta_{1}+\beta_{2}+\beta_{3}\right)-\gamma_{4} \beta_{1}
$$

Using this result, the income elasticity of the land value share derives as:

$$
\frac{\partial \log \mathrm{LVS}}{\partial \log \mathrm{I}}=\frac{\mathrm{SV}}{\mathrm{PV}}\left(1+\gamma_{2}+\gamma_{3}\right) \beta_{1}+\frac{\mathrm{SV}}{\mathrm{PV}} \beta_{2}+\frac{\mathrm{SV}}{\mathrm{PV}} \beta_{3}-\frac{\mathrm{SV}}{\mathrm{PV}} \beta_{5}
$$

In this formulation, $\beta_{5}$ can be recovered from results of $3 \mathrm{a}-3 \mathrm{~d}$ and multiplied by $\frac{\mathrm{SV}}{\mathrm{PV}}$ it constitutes the income elasticity of the land value share through the elasticity of the structures value, our house effect. 